\title{
Formation of cobalt ferrite nanopowders in an impinging-jets microreactor
}

\author{
K. I. Barashok ${ }^{1}$, V. V. Panchuk ${ }^{2}$, V. G. Semenov ${ }^{2}$, O. V. Almjasheva ${ }^{1,3, *}$, R. Sh. Abiev ${ }^{4,5}$ \\ ${ }^{1}$ Saint Petersburg State Electrotechnical University "LETI”, Professora Popova St., 5, \\ Saint Petersburg, 197376, Russia \\ ${ }^{2}$ Saint Petersburg State University, Universitetskaya emb., 7-9, Saint Petersburg, 199034, Russia \\ ${ }^{3}$ Ioffe Institute Politekhnicheskaya St. 26, Saint Petersburg, 194021, Russia \\ ${ }^{4}$ Saint Petersburg State Institute of Technology, Moskovsky Pr., 26, Saint Petersburg, 190013, Russia \\ ${ }^{5}$ Institute of Silicate Chemistry RAS, Makarova emb., 2 Saint Petersburg, 199034, Russia \\ *almjasheva@mail.ru, rufat.abiev@gmail.com
}

DOI 10.17586/2220-8054-2021-12-3-303-310

\begin{abstract}
The dependence of cobalt ferrite nanosized powder production process on the synthesis method and conditions was studied. The paper shows the possibility for producing nanocrystalline $\mathrm{CoFe}_{2} \mathrm{O}_{4}$ with an average particle size of $12 \mathrm{~nm}$ under conditions of an impinging-jets microreactor at room temperature. The influence exerted by the parameters of process implementation in the microreactor on phase formation in the $\mathrm{CoO}_{-} \mathrm{Fe}_{2} \mathrm{O}_{3}-$ $\mathrm{H}_{2} \mathrm{O}$ system was analyzed.
\end{abstract}

Keywords: cobalt ferrite, nanosized powders, impinging jet microreactor.

Received: 13 April 2021

Revised: 15 June 2021

\section{Introduction}

Nanocrystalline ferrite powders including cobalt ferrite powder are potentially widely used in medicine [1-8], catalysis [8-13], electronics, power industry and in other fields of engineering and technology [14-22]. For nanoparticles to be effectively used, as a rule, they should have not only small size but also quite narrow size distribution [3-5, 16, 23]. Therefore, it is of interest to study the formation processes of nanocrystalline cobalt-ferrite-based powder allowing the creation of slightly agglomerated crystalline nanoparticles with a narrow size distribution. Methods belonging to the group of "soft chemistry" techniques are often used for these purposes [13-19,24-34]. A method for combined hydrothermal and microwave treatment of hydroxides [31-35] is one of the promising methods for the synthesis of nanosized powders; when this method is used, the hydrothermal medium is heated due to exposure to the microwave radiation. The earlier studies $[35,36]$ showed that $\mathrm{CoFe}_{2} \mathrm{O}_{4}$ nanocrystals were already formed within the first minute of synthesis at a temperature of $130{ }^{\circ} \mathrm{C}$ in the mode of microwave heating of co-precipitated cobalt and iron hydroxides. Such high rate of synthesis of nanocrystalline $\mathrm{CoFe}_{2} \mathrm{O}_{4}$ was associated with the formation of prenucleation cluster hydroxides with a structure, which was similar to that of cobalt ferrite, in the initial mixture [35,36]. Another condition, in addition to the creation of nucleation clusters in the reaction medium, which provides a high rate of formation of the final product, is a decrease in the path length of the reagents and an increase in the rate of their transport in the reaction zone [37]. One of the ways to ensure the rapid course of chemical reactions is a high level of spatial contact of the initial components [24,35,36,40,41]. According to [42-44], it is possible to avoid spatial separation of the components during the synthesis of oxide nanoparticles resulting from the difference in $\mathrm{pH}$ values of hydroxide precipitation and variations in temperatures of their dehydration by using a method for microreactor synthesis with freely impinging jet-jets. Equipment of this type can provide for the rapid contact and micromixing of reagents, high level of reaction zone localization, and fast discharge of reaction products [42-49]. For example, the studies $[43,44]$ showed that the use of microreactor synthesis resulted in obtaining nanocrystalline cobalt ferrite with crystallite size of about $8 \mathrm{~nm}$ already at room temperature. Therefore, it is interesting to systematically study the influence exerted by the process parameters of synthesis in a freely impingingjet-jets microreactor on the formation process of nanocrystalline cobalt ferrite. In particular, it is interesting to analyze the influence of a pulsation mode of reagent supply, which showed the higher efficiency of microreactor synthesis in some cases [47]. 


\section{Experimental}

Cobalt ferrite was produced by coprecipitation from the mixture of aqueous solutions of $0.5 \mathrm{M}$ iron (III) nitrate $\left(\mathrm{Fe}\left(\mathrm{NO}_{3}\right)_{3}\right.$ (analytical reagent grade) and $0.25 \mathrm{M}$ cobalt (II) nitrate $\left(\mathrm{Co}\left(\mathrm{NO}_{3}\right)_{2}\right.$ (analytical reagent grade) ) with $1.3 \mathrm{M}$ sodium hydroxide $(\mathrm{NaOH}$, (analytical reagent grade)) in a freely impinging jet-jets microreactor, the design of which was described in [44]. The alkali solution with the above concentration with the reagent supply rates use provides for a certain alkali excess in the interaction zone as compared to reaction stoichiometry, which is required for precipitation completeness.

The mixture of salt solutions (solution No. 1) and $\mathrm{NaOH}$ solution (solution No. 2) were supplied with the use of two Heidolph 5201 peristaltic pumps with a Quick-S five-roller head with constant flow rates to the microreactor unit through the nipples on the opposite sides (Fig. 1) [44]. The internal diameters of the nozzles (2, 3 - Fig. 1) were $520-540 \mu \mathrm{m}$. The studies were performed in the microreactor made in two versions: without pulsations (Fig. 1a) and with pulsations with superposition of the pulsations on the liquid flow (Fig. 1b). In the second version, reagents were supplied to the interaction zone in the mode of reagent solution flows modulation, by coherent (with equal amplitude, frequency and phase) pulsations generated with the use of a pulsator 12 and two identical chambers with variable volume (bellows) 13. An idea of using the pulsation assembly when supplying the solutions to the reactor space consists in the fact that there takes place accelerated (as compared to uninterrupted supply of the solutions by the pumps) breaking up of jets to primary reagent drops 15 , which, when moving from the opposite sides with equal velocities and colliding, form secondary microdrops 16 as a result of interfusion. Such mode allows implementing the interaction process of salt solutions and the precipitator in a limited space of microdrops 16 with diameter of about 1 $2 \mathrm{~mm}$. The drops of reagent solutions from the opposite nipples were formed simultaneously due to the coherence of the generated oscillations. The pulsation frequency was varied in the range of $4.26-13.9 \mathrm{~Hz}$.

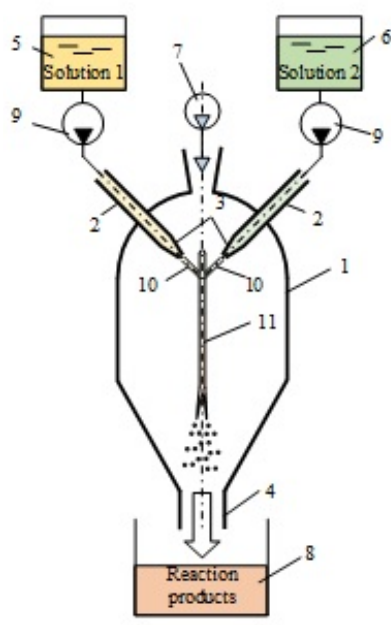

a

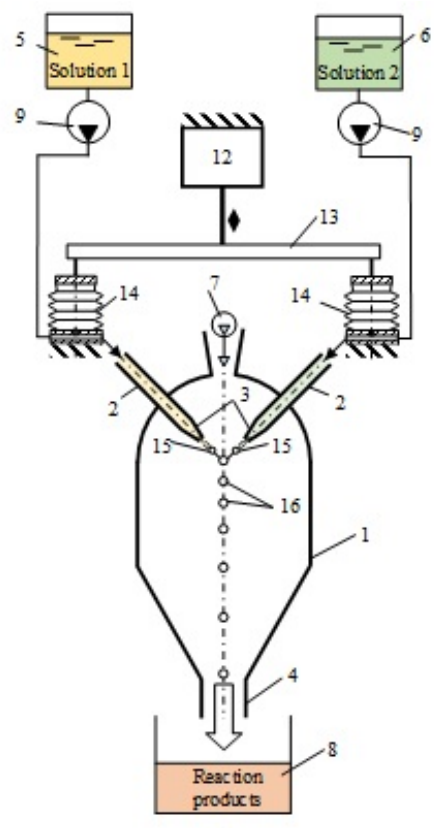

$b$

FIG. 1. Scheme of the microreactor unit: (a) - without the use of pulsations; (b) - with superposition of pulsations on the flow. 1 - cylinder-conic housing; 2 - nipples for supplying the initial components; 3 - nozzles; 4 - outlet for product discharge; 5,6 - vessels for solutions; 7 - purge gas blower; 8 - vessel for collecting the reaction products; 9 - pumps; 10 - jets; 11 - liquid sheet in free volume; 12 - drive of oscillation movements; 13 - crossbeam; 14 - chambers with variable volume (bellows); 15 - primary drops of individual solutions; 16 - secondary drops of the solution mixture

The precipitate obtained as a result of the solutions mixing was collected in a vessel under the microreactor unit, washed with distilled water to reach neutral $\mathrm{pH}$ and the absence of impurity ions, and dried at a temperature of $50{ }^{\circ} \mathrm{C}$.

A material produced by the method for direct precipitation from the aqueous solution mixture of iron and cobalt salts with aqueous sodium hydroxide solution was used as the reference sample. $\mathrm{NaOH}$ solution was added at constant 
mixing using a mechanical mixer until $\mathrm{pH}=8$ was reached. The obtained precipitate was washed also with distilled water and dried at a temperature of $50^{\circ} \mathrm{C}$.

The microstructure and elemental composition of the samples were determined using Quanta 200 scanning electron microscope (FEI Company) fitted out with EDAX X-ray spectral microanalysis attachment.

The phase composition of the samples was controlled by X-ray diffraction using SmartLab $3 \mathrm{X}$-ray diffractometer (CoK $K_{\alpha}$-radiation) (Rigaku Corporation). The peaks in the diffractogram were identified using PDWin 4.0 software complex and Crystallographica Search-Match package. The average crystallite size, i.e. the size of monocrystals, of which cobalt ferrite particles consisted, was determined as a value of the coherent scatter region, based on broadening of X-ray diffraction lines, using Scherrer formula.

The crystal size distribution was determined based on the data of X-ray diffraction of the samples using MAUD software.

Mössbauer spectra were recorded using a spectrometer by WISSEL in the permanent acceleration mode, at the room temperature. ${ }^{57} \mathrm{Co}$ in Rh-matrix with activity of $30 \mathrm{mCi}$ was used as the source. The mathematical processing of the experimental spectra was performed using MOSSFIT software package [50]. The velocity scale of the spectrometer was calibrated using $\alpha$-Fe foil in the room temperature. The values of chemical shifts are presented relative to $\alpha$-Fe.

\section{Results and discussion}

According to elemental analysis data (Table 1), the Co:Fe ratio for all samples obtained both by direct precipitation and under conditions of microreactor synthesis, taking into account the method error, conforms to stoichiometry preset during the synthesis. Sodium is not detected in the sample within the sensitivity of X-ray spectral analysis, which evidences practically full removal of impurity solution components from the obtained powders.

X-ray diffractograms of the obtained samples are presented in Fig. 2. The X-ray diffractogram of the sample obtained by direct coprecipitation of iron and cobalt hydroxides with $\mathrm{NaOH}$ solution (Fig. 2, curve 1) shows broad $\mathrm{X}$-ray maxima of low intensity which are evidence of the presence of Co-Fe-layered double hydroxide (LDH) [51,52], $\gamma-\mathrm{Fe}_{2} \mathrm{O}_{3}$ and cobalt ferrite $\left(\mathrm{CoFe}_{2} \mathrm{O}_{4}\right)$ in the sample. At the same time, the analysis of X-ray diffraction line profile evidences of the fact that the sample is mainly in the $\mathrm{X}$-ray amorphous condition.

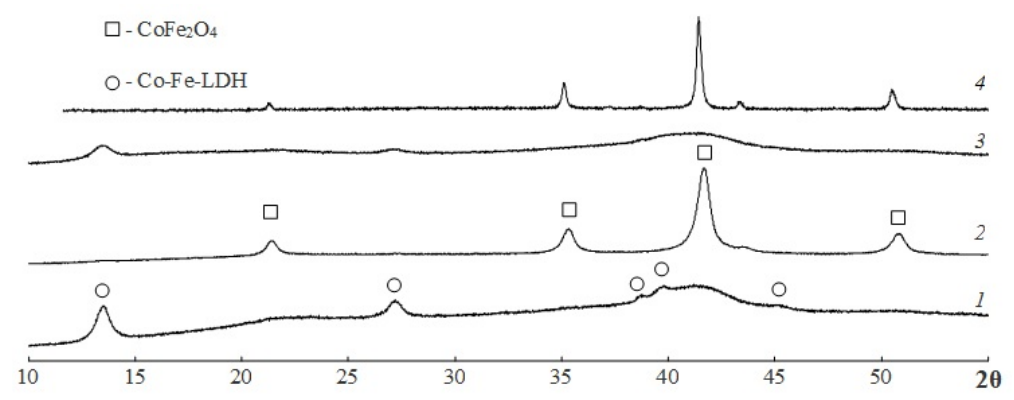

FIG. 2. X-ray diffractograms of the samples obtained in the process of 1 - direct precipitation; 2 - microreactor synthesis with continuously impinging-jets; 3 - microreactor synthesis in pulsation mode $(\nu=13.9 \mathrm{~Hz}) ; 4-$ thermal treatment of the sample synthesized under conditions of a microreactor, in the pulsation mode $(\nu=13.9 \mathrm{~Hz})$ at a temperature of $800{ }^{\circ} \mathrm{C}$ for $1 \mathrm{~h}$

The analysis of X-ray diffractogram of the sample obtained using the microreactor without pulsation mode (Fig. 2, curve 2) is evidence of the fact that the interaction of reagents in the sheet being formed during jet collision results in production of nanocrystalline cobalt ferrite with the average crystallite size of about $12 \mathrm{~nm}$. However, the analysis of the dependence presented in Fig. 3shows evidence of quite broad crystallite size distribution.

The use of the pulsation mode when supplying the reagents during the microreactor synthesis leads to the formation of a practically X-ray amorphous product. X-ray diffractograms of the samples obtained with different pulsation frequencies show only low-intensive halo in the region of maximal peaks corresponding to $\mathrm{Co}-\mathrm{Fe}-$ layered double hydroxide and cobalt ferrite. The typical view of X-ray diffractogram of the samples $3-5$ (see Table 1) is presented in Fig. 2 (curve 3).

The Mössbauer spectra of powders obtained both by the method for direct precipitation and with the use of microreactor synthesis is presented in Fig. 4. Fig. 4 shows also the results of the decomposition of the experimental spectra to components corresponding to iron atoms in different local surroundings. The Mössbauer parameters of iron-containing phases are presented in Table 1. The quantitative assessment of the relative iron content in different phases is performed within the accuracy of the difference in values of Mössbauer factor $f_{M}$. 


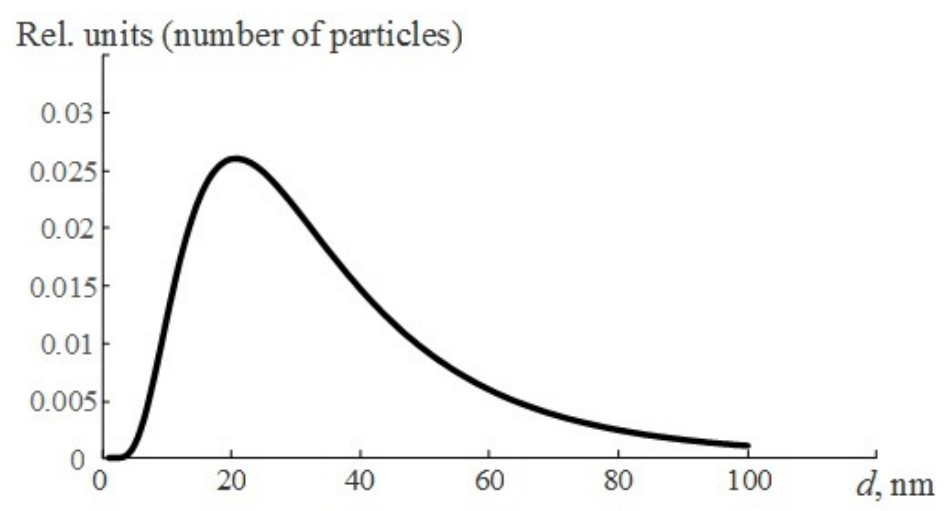

FIG. 3. Size distribution of $\mathrm{CoFe}_{2} \mathrm{O}_{4}$ crystallites obtained by the method of microreactor synthesis with continuously impinging-jets

The Mössbauer spectrum for the sample obtained under conditions of microreactor synthesis without the pulsation mode is a superposition of sextets corresponding to the condition of iron atoms in octa- and tetra-positions in cobalt ferrite structure. The values of magnetic hyperfine fields $\left(H_{e f f}\right)$ of these sextets depend not only on the differences in local surroundings of iron nuclei corresponding to them but also on magnetic crystal sizes. The value $H_{\text {eff }}$ decreases when crystals pass to single-domain (superparamagnet) condition, in which magnet locking temperature depends on crystal size [53]. Moreover, the smaller the crystal size is, the lower the value $H_{e f f}$ is down to its full disappearance. Such behavior of $H_{\text {eff }}$ occurs for magnet crystals, in which the rate of direction change of the total magnetic moment is much larger than the nucleus lifetime in the excited condition $\left(\tau \sim 10^{-9} \mathrm{~s}\right)$. This critical size for $\mathrm{CoFe}_{2} \mathrm{O}_{4}$ is about $6 \mathrm{~nm}[54,55]$. Thus, comparison of sextet parameters (Fig. 4, Table 1) with the data of [55] allows one to conclude that the maximum size of $\mathrm{CoFe}_{2} \mathrm{O}_{4}$ crystallites obtained by microreactor synthesis is less than $50 \mathrm{~nm}$. In addition, the presence of a sextet with low $H_{\text {eff }}(39.3 \mathrm{~T})$ is explained by broad crystallite size distribution. These results are in good agreement with the X-ray diffraction data (Fig. 3).

The Mössbauer spectrum represents doublet superposition for all other samples obtained both by the method for direct precipitation and by using microreactor synthesis in the pulsation mode (Fig. 4, Table 1). The analysis of experimental spectra allows distinguishing a doublet corresponding to iron atom condition in the structure of $\mathrm{Co}-\mathrm{Fe}$ layered double hydroxide [48] and doublets evidencing the presence of small $\mathrm{CoFe}_{2} \mathrm{O}_{4}$ clusters with crystallite sizes corresponding to the superparamagnet condition [55].

According to the study [54], the critical size of superparamagnetism for $\mathrm{CoFe}_{2} \mathrm{O}_{4}$ is about $14 \mathrm{~nm}$. In the [55] the authors observed two doublets with parameters $I_{S}($ tetr $)=0.258, Q_{S}($ tetr $)=1.943$ and $I_{S}(\operatorname{tetr})=0.326, Q_{S}($ tetr $)=$ 0.653 for cobalt ferrite with crystallite size of about $6 \mathrm{~nm}$. The noticeable difference between the parameters of Mössbauer spectra presented in Table and the parameters in [55] may be associated with several factors, e.g., with significantly smaller size of clusters with cobalt ferrite structure as compared to the size of $\mathrm{CoFe}_{2} \mathrm{O}_{4}$ crystallites described in the study [55]. It is possible that these differences are caused by different population degree with cobalt and iron ions in the octa- and tetra-positions in the spinel structure, which can be explained, among other factors, by peculiarities of synthesis conditions.

Thus, the analysis of the presented data is evidence of the fact that when the methods for direct coprecipitation and microreactor synthesis in jet pulsation mode are used, formation of small clusters with cobalt ferrite structure with different population degree in octa- and tetra-positions is observed at the stage of mixing of the reagents (cobalt and iron nitrates solution with $\mathrm{NaOH}$ solution), which is confirmed by the deviation of quadrupolar splitting values from the data presented in [55]. At the same time, spatial component separation associated with the formation of the phase of Co-Fe-layered double hydroxide takes place, apparently, in the greater part of the system and, as a result, the mechanism of cobalt ferrite formation changes as compared to the mode of continuous mixing of reagent streams described in [51,52].

The described difference in phase formation processes in the microreactor with continuously impinging-jets [43, 44] and when the pulsation mode is used can be associated with the fact that the sizes of colliding drops are about $1 \mathrm{~mm}$ and the energy dissipation rate in such case is significantly less than that when microjets collide with the formation of the liquid sheet with a thickness of about $20 \mu \mathrm{m}$. This difference results in the fact that it is not possible to implement hydrodynamic conditions leading to the formation of the microreactor in the pulsation mode [42,43]. This leads, in its turn, to spatial separation of the reaction system components, and the formation of $\mathrm{CoFe}_{2} \mathrm{O}_{4}$ will take place not due to the coalescence of small clusters with cobalt ferrite structure as it was mentioned in $[35,36]$ but according to the 


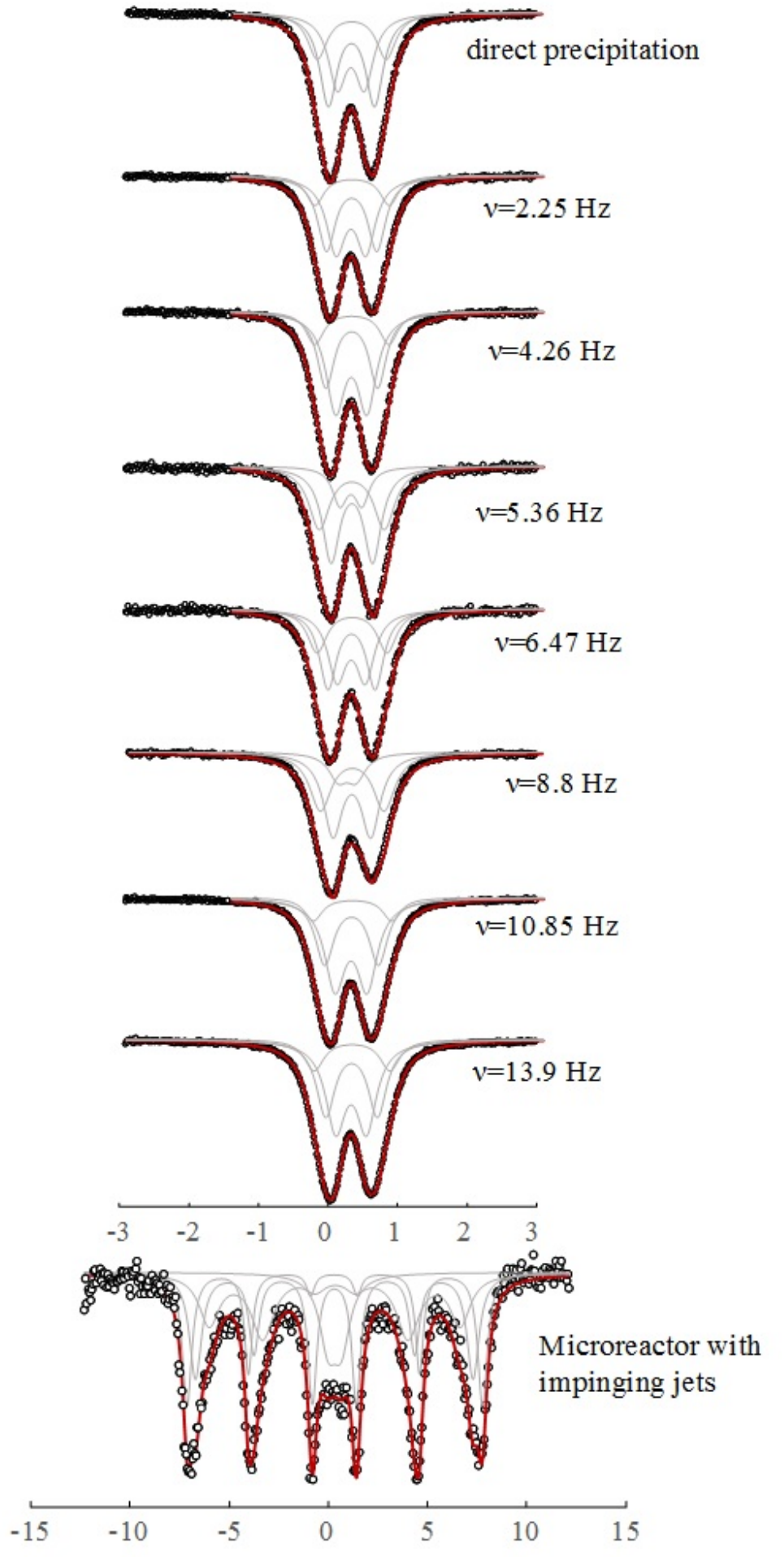

FIG. 4. Mössbauer spectra of the samples 
TABLE 1. The parameters of Mössbauer spectra of the samples (determination error for $I_{s} \pm$ $0.002 \mathrm{~mm} / \mathrm{s} ; Q_{s} \pm 0.005 \mathrm{~mm} / \mathrm{s} ; H_{e f f} \pm 0.1 \mathrm{~T}$ )

\begin{tabular}{|c|c|c|c|c|c|c|c|}
\hline \multirow{2}{*}{$\begin{array}{l}\text { Synthesis } \\
\text { conditions }\end{array}$} & \multirow[t]{2}{*}{$\mathrm{Fe} / \mathrm{Co}$} & \multirow[t]{2}{*}{ Phases } & \multicolumn{4}{|c|}{$\begin{array}{c}\text { Mössbauer parameters for iron atoms in various } \\
\text { local environment }\end{array}$} & \multirow{2}{*}{$\begin{array}{l}\text { Identification of } \\
\text { local environments } \\
\text { of iron atoms }\end{array}$} \\
\hline & & & $I_{S}(\mathrm{~mm} / \mathrm{s})$ & $Q_{S}(\mathrm{~mm} / \mathrm{s})$ & $H_{e f f}(\mathrm{~T})$ & $\%$ & \\
\hline \multirow{3}{*}{$\begin{array}{l}\text { Direct } \\
\text { precipi } \\
\text { tation }\end{array}$} & \multirow{3}{*}{2.05} & \multirow{3}{*}{$\begin{array}{c}\mathrm{Co}-\mathrm{Fe}- \\
\mathrm{LDH}, \\
\mathrm{CoFe}_{2} \mathrm{O}_{4}\end{array}$} & 0.339 & 0.665 & - & 43.08 & \multirow{2}{*}{$\mathrm{CoFe}_{2} \mathrm{O}_{4}$} \\
\hline & & & 0.343 & 0.994 & - & 23.43 & \\
\hline & & & 0.330 & 0.388 & - & 33.50 & $\mathrm{Co}-\mathrm{Fe}-\mathrm{LDH}$ \\
\hline \multirow{4}{*}{$\operatorname{MS}(\nu=0)$} & \multirow{4}{*}{2.03} & \multirow{4}{*}{$\mathrm{CoFe}_{2} \mathrm{O}_{4}$} & 0.307 & -0.042 & 46.272 & 24.05 & \multirow{4}{*}{$\mathrm{CoFe}_{2} \mathrm{O}_{4}$} \\
\hline & & & 0.303 & 0.004 & 43.462 & 34.53 & \\
\hline & & & 0.337 & 0.031 & 39.302 & 29.46 & \\
\hline & & & 0.322 & 0.674 & & 11.96 & \\
\hline \multirow{3}{*}{$\operatorname{MS}(\nu=4.26)$} & \multirow{3}{*}{2.13} & \multirow{3}{*}{$\begin{array}{c}\text { am. ph., trace } \\
\text { Co-Fe-LDH, } \\
\mathrm{CoFe}_{2} \mathrm{O}_{4}\end{array}$} & 0.340 & 0.746 & - & 35.63 & \multirow{2}{*}{$\mathrm{CoFe}_{2} \mathrm{O}_{4}$} \\
\hline & & & 0.341 & 1.067 & - & 15.83 & \\
\hline & & & 0.332 & 0.451 & - & 48.54 & Co-Fe-LDH \\
\hline \multirow{3}{*}{$\operatorname{MS}(\nu=5.36)$} & \multirow{3}{*}{2.19} & \multirow{3}{*}{$\begin{array}{c}\text { am. ph., trace } \\
\text { Co-Fe-LDH, } \\
\mathrm{CoFe}_{2} \mathrm{O}_{4}\end{array}$} & 0.342 & 0.599 & - & 46.06 & \multirow{2}{*}{$\mathrm{CoFe}_{2} \mathrm{O}_{4}$} \\
\hline & & & 0.341 & 0.936 & - & 38.00 & \\
\hline & & & 0.327 & 0.317 & - & 15.94 & Co-Fe-LDH \\
\hline \multirow{3}{*}{$\operatorname{MS}(\nu=6.47)$} & \multirow{3}{*}{2.01} & \multirow{3}{*}{$\begin{array}{c}\text { am. ph., trace } \\
\text { Co-Fe-CDG, } \\
\mathrm{CoFe}_{2} \mathrm{O}_{4}\end{array}$} & 0.336 & 0.678 & - & 40.32 & \multirow{2}{*}{$\mathrm{CoFe}_{2} \mathrm{O}_{4}$} \\
\hline & & & 0.343 & 1.007 & - & 23.88 & \\
\hline & & & 0.330 & 0.406 & - & 35.80 & Co-Fe-LDH \\
\hline \multirow{3}{*}{$\operatorname{MS}(\nu=10.85)$} & \multirow{3}{*}{2.07} & am. ph., trace & 0.340 & 0.774 & - & 35.94 & \multirow{2}{*}{$\mathrm{CoFe}_{2} \mathrm{O}_{4}$} \\
\hline & & Co-Fe-LDH, & 0.354 & 1.125 & - & 12.26 & \\
\hline & & $\mathrm{CoFe}_{2} \mathrm{O}_{4}$ & 0.332 & 0.463 & - & 51.80 & $\mathrm{Co}-\mathrm{Fe}-\mathrm{CDG}$ \\
\hline \multirow{3}{*}{$\operatorname{MS}(\nu=13.90)$} & \multirow{3}{*}{2.03} & am. ph., trace & 0.338 & 0.744 & - & 38.36 & \multirow{2}{*}{$\mathrm{CoFe}_{2} \mathrm{O}_{4}$} \\
\hline & & Co-Fe-LDH, & 0.345 & 1.091 & - & 15.79 & \\
\hline & & $\mathrm{CoFe}_{2} \mathrm{O}_{4}$ & 0.331 & 0.442 & - & 45.85 & Co-Fe-LDH \\
\hline
\end{tabular}

Mossbauer parameters of comparison crystals $\mathrm{CoFe}_{2} \mathrm{O}_{4}$ : ${ }^{*}$ less $6 \mathrm{~nm} I_{S}($ tetr $)=0.258, Q_{S}($ tetr $)=1.943 ; I_{S}($ octa $)=0.326$,

$Q_{S}($ octa $)=0.653[55] ;{ }^{* *}$ nanocrystals $I_{S}(\mathrm{~A})=0.24, Q_{S}(\mathrm{~A})=0.04 ; I_{S}(\mathrm{~B})=0.37, Q_{S}(\mathrm{~B})=0.03[55] ;{ }^{* * *} \mathrm{Co}-\mathrm{Fe}-\mathrm{CDG} I_{S}=0.349$,

$Q_{S}($ tetr $)=0.497[51,52]$

mechanism of solid-phase interaction which is similar to the formation process of magnesium ferrite described in the study [40]. The implementation of such formation mechanism will require a stage involving long thermal treatment.

\section{Conclusions}

Thus, it is possible to conclude that the use of the method for microreactor synthesis with continuously impingingjets allows one to obtain nanosized cobalt ferrite crystals at room temperature. The need to use the pulsation mode, at least in the form that was used in this work for the synthesis of $\mathrm{CoFe}_{2} \mathrm{O}_{4}$ nanoparticles, does not allow realization of the advantages of microreactor synthesis.

\section{Acknowledgements}

The authors express their gratitude to Zimina O. Yu. for the helping with the experiment and V. V. Gusarov for the attention he paid to the work and for his help in the interpretation of the results. 


\section{References}

[1] Sharifi I., Shokrollahi H., Amiri S. Ferrite-based magnetic nanofluids used in hyperthermia applications. Journal of Magnetism and Magnetic Materials, 2012, 324(6), P. 903-915.

[2] Amiri M., Akbari A., Ahmadi M., Pardakhti A., Salavati-Niasari M. Synthesis and in vitro evaluation of a novel magnetic drug delivery system; proecological method for the preparation of $\mathrm{CoFe}_{2} \mathrm{O}_{4}$ nanostructures. Journal of Molecular Liquids, 2018, 249, P. 1151-1160.

[3] Amiri S., Shokrollahi H. The role of cobalt ferrite magnetic nanoparticles in medical science. Materials Science and Engineering: C, 2012, 33(1), P. 1-8.

[4] Oh Y., Moorthy M.S., Manivasagan P., Bharathiraja S., Oh J. Magnetic hyperthermia and pH-responsive effective drug delivery to the subcellular level of human breast cancer cells by modified $\mathrm{CoFe}_{2} \mathrm{O}_{4}$ nanoparticles. Biochimie, 2017, 133, P. 7-19.

[5] Drašler B., Drobne D., Novak S., et al. Effects of magnetic cobalt ferrite nanoparticles on biological and artificial lipid membranes. International Journal of Nanomedicine, 2014, 9(1), P. 1559-1581.

[6] Guglielmo C.D., López D. R., Lapuente J. De., Llobet Mallafre J. M., Suàrez M. B. Embryotoxicity of cobalt ferrite and gold nanoparticles: A first in vitro approach. Reproductive Toxicology, 2010, 30(2), P. 271-276.

[7] Sanpo N., Berndt C. C., Wen C., Wang J. Transition metal-substituted cobalt ferrite nanoparticles for biomedical applications. Acta Biomaterialia, 2013, 9(3), P. 5830-5837.

[8] Sincai, M., Ganga, D., Bica, D., Vekas, L. The antitumor effect of locoregional magnetic cobalt ferrite in dog mammary adenocarcinoma. Journal of Magnetism and Magnetic Materials, 2001, 225(1-2), P. 235-240.

[9] Amiri M., Salavati-Niasari M., Akbari A. A magnetic $\mathrm{CoFe}_{2} \mathrm{O}_{4} / \mathrm{SiO}_{2}$ nanocomposite fabricated by the sol-gel method for electrocatalytic oxidation and determination of L-cysteine. Microchimica Acta, 2017, 184(3), P. 825-833.

[10] Chen Y., Sun J., Zhang Y., Zheng S., Wang B., Chen Z., Xue Y., Chen M., Abbas M., Chen J. CoFe ${ }_{2} \mathrm{O}_{4}$ nanoarray catalysts for Fischer-Tropsch synthesis. Journal of Fuel Chemistry and Technology, 2017, 45(9), P. 1082-1087.

[11] Chen H.D., Xu J.K., Wei J.Q., Wang P.F., Han Y.B., Xu J.C., Hong B., Jin H.X., Jina D.F., Peng X.L., Li J., Yang Y.T., Ge H.L., Wang X.Q. Mesoporous $\mathrm{CoFe}_{2} \mathrm{O}_{4}$ nanowires: Nanocasting synthesis, magnetic separation and enhanced catalytic degradation for ciprofloxacin. Journal of Physics and Chemistry of Solids, 2019, 132, P. 138-144.

[12] Tan X., Wang X., Liu Q., Zhou J., Zhang P., Zheng S., Miao S. Bio-gel template synthesis of $\mathrm{CoFe}_{2} \mathrm{O}_{4}$ nano-catalysts and application in aerobic oxidation of cyclohexane. International Journal of Hydrogen Energy, 2107, 42(30), P. 19001-19009.

[13] Huang Y., Yang W., Yu Y., Haov S. Ordered mesoporous spinel CoFe $\mathrm{CO}_{4}$ as efficient electrocatalyst for the oxygen evolution reaction. Journal of Electroanalytical Chemistry, 2019, 840, P. 409-414.

[14] Xavier S., Thankachan S., Jacob B.P., Mohammed E.M. Effect of sintering temperature on the structural and magnetic properties of cobalt ferrite nanoparticles. Nanosystems: Physics, Chemistry, Mathematics, 2013, 4(3), P. 430-437.

[15] Song N., Gu S., Wu Q., Li C., Jhou J. Facile synthesis and high-frequency performance of $\mathrm{CoFe}_{2} \mathrm{O}_{4}$ nanocubes with different size. Journal of Magnetism and Magnetic Materials, 2018, 451, P. 793-798.

[16] Song N., Gu S., Zhou J., Xia W., Zhang P. Achieving a high cutting-off frequency in the oriented CoFe $\mathrm{O}_{4}$ nanocubes. Journal of Applied Physics Letter, 2017, 111, P. 133108.

[17] Karthick R., Ramachandran K., Srinivasan R. Study of faraday effect on $\mathrm{Co}_{1-x} \mathrm{Zn}_{x} \mathrm{Fe}_{2} \mathrm{O}_{4}$ nanoferrofluids. Nanosystems: Physics, Chemistry, Mathematics, 2016, 7(4), P. 624-628.

[18] Ojha Vibha H., Kant K. Mohan. Temperature dependent magnetic properties of superparamagnetic $\mathrm{CoFe}_{2} \mathrm{O}_{4}$ nanoparticles. Physica B: Condensed Matter., 2019, 567, P. 87-94.

[19] Lavela P., Tirado J.L. CoFe $\mathrm{O}_{4}$ and $\mathrm{NiFe}_{2} \mathrm{O}_{4}$ synthesized by sol-gel procedures for their use as anode materials for Li ion batteries. J. Power Sources., 2007, 172(1), P. 379-387.

[20] Chauhan C.C., Jotania R.B. Structural and magnetic properties of $\mathrm{BaCo}_{2-x} \mathrm{Ni}_{x} \mathrm{Fe}_{16} \mathrm{O}_{27}$ hexagonal ferrite prepared by a simple heat treatment method. Nanosystems: Physics, Chemistry, Mathematics, 2016, 7(4), P. 595-598.

[21] Vasylenko I.V., Kazakevych M.L., Pavlishchuk, V.V. Design of ferrofluids and luminescent ferrofluids derived from $\mathrm{CoFe}_{2} \mathrm{O}_{4}$ nanoparticles for nondestructive defect monitoring. Theoretical and Experimental Chemistry, 2019, 54(6), P. 365-368.

[22] Murugesan C., Perumal M., Chandrasekaran G. Structural, dielectric and magnetic properties of cobalt ferrite prepared using auto combustion and ceramic route. J. Physica B: Condensed Matter., 2014, 448, P. 53-56.

[23] Gofman I.V., Nikolaeva A.L., Khripunov A.K., Yakimansky A.V., Ivan'kova E.M., D.P. Romanov, Ivanova O.S., Teplonogova M.A., Ivanov V.K. Impact of nano-sized cerium oxide on physico-mechanical characteristics and thermal properties of the bacterial cellulose films. Nanosystems: Physics, Chemistry, Mathematics, 2018, 9(6), P. 754-762.

[24] Gingasu D., Mindru I., Mocioiua O.C., Preda S., Stanica N., Patron L., Ianculescu A., Oprea O., Nita S., Paraschiv I., Popa M., Saviuc K., Bleotu C., Chifiriuc M.C. Synthesis of nanocrystalline cobalt ferrite through soft chemistry methods: A green chemistry approach using sesame seed extract. Materials Chemistry and Physics, 2016, 182, P. 219-230.

[25] Popkov V.I., Almjasheva O.V. Formation mechanism of $\mathrm{YFeO}_{3}$ nanoparticles under the hydrothermal condition. Nanosystems: Physics, Chemistry, Mathematics, 2014, 5(5), P. 703-708.

[26] Nguen Anh Tien, Mittova I.Ya., Al'myasheva O.V. Influence of the synthesis conditions on the particle size and morphology of yttrium orthoferrite obtained from aqueous solutions. Russian Journal of Applied Chemistry, 2009, 82(11), P. 1915-1918.

[27] Kim Y.I., Kim D., Lee C.S. Synthesis and characterization of $\mathrm{CoFe}_{2} \mathrm{O}_{4}$ magnetic nanoparticles prepared by temperature-controlled coprecipitation method. Phys. B Condens. Matter., 2003, 337, P. 42-51.

[28] Manova E., Kunev B., Paneva D., Mitov I., Petrov L., Estourns C., D’Orlans C., Rehspringer J.L., Kurmoo M. Mechano-synthesis, characterization, and magnetic properties of nanoparticles of cobalt ferrite $\mathrm{CoFe}_{2} \mathrm{O}_{4}$. Chem. Mater, 2004, 16(26), P. 5689-5692.

[29] Nguyen Anh Tien, Chau Hong Diem, Nguyen Thi Truc Linh, Mittova V.O., Do Tra Huong, Mittova I.Ya. Structural and magnetic properties of $\mathrm{YFe}_{1-x} \mathrm{Co}_{x} \mathrm{O}_{3}(0.1 \leq x \leq 0.5)$ perovskite nanomaterials synthesized by co-precipitation method. Nanosystems: Physics, Chemistry, Mathematics., 2018, 9(3), P. 424-429.

[30] Saffari J., Ghanbari D., Mir N., Khandan-Barani K. Sonochemical synthesis of $\mathrm{CoFe}_{2} \mathrm{O}_{4}$ nanoparticles and their application in magnetic polystyrene nanocomposites. J. Ind. Eng. Chem., 2014, 20, P. 4119-4123. 
[31] Kalpanadevi K., Sinduja C.R., Manimekalai R. A facile thermal decomposition route to synthesise $\mathrm{CoFe}_{2} \mathrm{O}_{4}$ nanostructures. Mater Sci-Pol., 2014, 32(1), P. 34-38.

[32] Meskin P.E., Gavrilov A.I., Maksimov V.D., Ivanov V.K., Churagulov B.P. Hydrothermal/microwave and hydrothermal/ultrasonic synthesis of nanocrystalline titania, zirconia, and hafnia. Russian Journal of Inorganic Chemistry, 2007, 52(11), P. $1648-1656$.

[33] Meng L.-Y., Wang B., Ma M.-G., Lin K.-L. The progress of microwave-assisted hydrothermal method in the synthesis of functional nanomaterials. Materials Today Chemistry, 2016, 1-2, P. 63-83.

[34] Ivanov V.K., Polezhaeva O.S., Gil' D.O., Kopitsa G.P., Tret'yakov Yu.D. Hydrothermal microwave synthesis of nanocrystalline cerium dioxide. Doklady Chemistry, 2009, 426(2), P. 131-133.

[35] Kuznetsova V.A., Almjasheva O.V., Gusarov V.V. Influence of microwave and ultrasonic treatment on the formation of $\mathrm{CoFe}_{2} \mathrm{O}_{4}$ under hydrothermal conditions. Glass Physics and Chemistry, 2009, 35(2), P. 205-209.

[36] Almjasheva O.V., Gusarov, V.V. Prenucleation formations in control over synthesis of $\mathrm{CoFe}_{2} \mathrm{O}_{4}$ nanocrystalline powders. Russ. J. Appl. Chem., 2016, 89(6), P. 851-856.

[37] Gusarov V.V. Fast solid-phase chemical reactions. Russ. J. Gen. Chem., 1997, 67(12), P. 1846-1851.

[38] Gusarov V.V., Ishutina Zh.N., Malkov A.A., Malygin A.A. Solid-phase reaction of mullite formation in nanosized composite films. Dokl. Phys. Chem., 1997, 357(1-3), P. 360-363.

[39] Gusarov V.V., Malkov A.A., Ishutina Zh.N., Malygin A.A. Phase formation in a nanosize silicon oxide film on the surface of aluminum oxide. Tech. Phys. Lett., 1998, 24(1), P. 1-3.

[40] Komlev A.A., Panchuk V. V., Semenov V.G., Almjasheva O.V., Gusarov V.V. Effect of the sequence of chemical transformations on the spatial segregation of components and formation of periclase-spinel nanopowders in the $\mathrm{MgO}-\mathrm{Fe}_{2} \mathrm{O}_{3}-\mathrm{H}_{2} \mathrm{O}$ system. Russ. J Appl. Chem., 2016, 89(12), P. 1930-1936.

[41] Krasilin A.A., Almjasheva O.V., Gusarov V.V. Effect of the structure of precursors on the formation of nanotubular magnesium hydrosilicate. Inorganic Materials, 2011, 47(10), P. 1111-1115.

[42] Proskurina O.V., Nogovitsin I.V., Il'ina T.S., Danilovich D.P., Abiev R.Sh., Gusarov V.V. Formation of BiFeO 3 nanoparticles using impinging jets microreactor. Russian Journal of General Chemistry, 2018, 88(10), P. 2139-2143.

[43] Abiev R.S., Almyasheva O.V., Izotova S.G., Gusarov V.V. Synthesis of cobalt ferrite nanoparticles by means of confined impinging-jets reactors. J. Chem. Tech. App., 2017, 1(1), P. 7-13.

[44] Abiev R.Sh., Al'myasheva O.V., Gusarov V.V., Izotova S.G. Method of producing nanopowder of cobalt ferrite and microreactor to this end. RF Patent 2625981, Bull. 20, 20.07.2017. https://patents.google.com/patent/RU2625981C1/en.

[45] Ashgriz N., Brocklehurst W., Talley D. Mixing mechanisms in a pair of impinging jets. J. Propul. Power., 2001, 17(3), P. 736.

[46] Handbook of Atomization and Sprays. Ed. N. Ashgriz, Toronto, Springer Science Business Media, LLC, 2011. Ch. 30 , P. 685.

[47] Erkoc E., Fonte C.P., Dias M.M., Lopes J.C.B., Santos R.J. Numerical study of active mixing over a dynamic flow field in a T-jets mixer Induction of resonance. Chem. Eng. Res. Design., 2016, 106, P. 74.

[48] Ravi Kumar D.V., Prasad B.L.V., Kulkarni A.A. Impinging jet micromixer for flow synthesis of nanocrystalline MgO: role of mixing/impingement Zone. Ind. Eng. Chem. Res., 2013, 52, P. 17376.

[49] Kolodziej P., Yang W.P., Macosko C.W., Wellinghoff S.T. Impingement mixing and its effect on the microstructure of RIM polyurethanes. J. Polymer Sci. B, 1986, 24(10), P. 2359.

[50] Semenov V.G., Moskvin L.N., Efimov A.A. Analytical potential of Mössbauer spectroscopy. Russian Chemical Reviews, 2006, 75(4), P. 317327.

[51] Gong C., Chen F., Yang Q., Luo K., Yao F., Wang S., Wang X., Wu J., Li X., Wang D., Zeng G. Heterogeneous activation of peroxymonosulfate by Fe-Co layered doubled hydroxide for efficient catalytic degradation of Rhoadmine B. Chemical Engineering Journal, 2017, 321, P. 222232.

[52] Carvalho D.C., Ferreira N.A., Filho J.M., Ferreira O.P., Soares J.M., Oliveira A.C. Ni-Fe and Co-Fe binary oxides derived from layered doublehydroxides and their catalytic evaluation for hydrogen production. Catalysis Today, 2015, 250, P. $155-165$.

[53] Lyubutin I.S., Starchikov S.S., Lin C.-R., Gervits N.E., Korotkov N.Yu., Bukreeva T.V. Structural and magnetic properties of iron oxide nanoparticles in shells of hollow microcapsules designed for biomedical applications. Croat. Chem. Acta., $2015,88(4)$, P. $397-403$.

[54] Koch C.D. Structures and properties of anionic clay minerals. Hyperfine Interactions, 1998, 117, P. $131-157$.

[55] Vasundhara K., Achary S.N., Deshpande S.K, Babu P.D., Meena S.S., Tyagi A.K. Size dependent magnetic and dielectric properties of nano $\mathrm{CoFe}_{2} \mathrm{O}_{4}$ prepared by a salt assisted gel-combustion method. J. Appl. Phys., 2013, 113, P. 194101. 